the value $B-\ln c$ in the expression of the logarithm of equivalent conductivity:

$$
\ln \frac{k}{c}=-\frac{A}{T}+(B-\ln c)
$$

(in which $T$ is temperature, $c$ sodium concentration, $A$ and $B$ constants). Nevertheless, the equivalent conductivity of glass greatly increases owing to the decrease of energy of dissociation of borates as a result of the interaction of their molecules. Experimentally it is shown in the fall of the coefficient $A \cong \frac{E}{4} \cdot 1,5$

It is found that the dissociation energy $E$ falls with the increase of molecular concentration of the polar molecules of borates $m$ (per cm. ${ }^{3}$ of glass) according to the equation:

$$
E=\frac{3 \cdot 6}{\sqrt{ } m} \text { cal. }
$$

The transition from the vitreous to the crystalline state is followed by the disappearance of the free positions. $^{3}$ The fall of conductivity to be expected in this case is shown experimentally to take place in the system $\mathrm{Na}_{2} \mathrm{O}+\mathrm{SiO}_{2} \cdot{ }^{6}$

It seems that the maximum of the rate of solution corresponds to the intermediate region of concentration in which the $\mathrm{B}_{2} \mathrm{O}_{3}$ monomolecular layers disappear; the molecules of borates, which were formerly separated from each other, are now drawn together and begin to interact; the van der Vaals' cohesion forces between the $\mathrm{B}_{2} \mathrm{O}_{3}$ molecules in glass are replaced by forces acting among the polar molecules of sodium borates. R. L. MüLLER.

Institute of Chemical Physics, Leningrad.

1 S. Schtschukarew u. R. Müller, Z. phys. Chem., 150 A, 439; 1930. 2 G. Tamman, Z. anorg. Chem., 90, $297 ; 1915$.

3 G. Tamman u. L. Jenkel, Z, anorg. Chem., 184, 716; $1929: 186$, $171 ; 1930$.

G. v. Hevesy, Z. Physik., 2, 178; 1920

J. Frenkel, Z. Physik., 35, 652; 1924.

R. Schwarz u. J. Halberstadt, Z, anorg. Chem., 199, 33 ; 1931.

\section{Application of the Electrometer Triode to the Measurement of High Resistance}

IN some experiments made by us on the application of the electrometer triode to the measurement of the ionisation produced by radioactive substance and X-rays, alcohol xylol resistances of the order $10^{3}-10^{6}$ megohms have been employed. A method of measur. ing such resistances has been devised, in which use is made of the very high grid-filament resistance of the triode. The arrangement is indicated in Fig. 1. $R_{1}$ is a known resistance, $R_{2}$ is the resistance to be determined. With the potentiometer short-circuited and the key $K$ open, the normal anode current is first balanced by variation of the resistance $Z$ in the shortcircuit $G Z$, so that the galvanometer indicates zero. The key $K$ is now closed, and the current in the circuit $E R_{1} R_{2}$ alters the voltage of the grid by an amount equal to the voltage drop across $R_{1}$. The anode current is thereby altered, and the galvanometer is deflected. The grid is now restored to its original potential, by applying to it a potential by means of the potentiometer $P$, the reading of the potentiometer $e$ being a measure of the voltage across $R_{1}$. Obviously then

$$
R_{2}=R_{1}(E-e) / e \text {. }
$$

Resistances up to $10^{6}$ megohms have been measured in this manner, the procedure being to construct a series of alcohol-xylol resistances of the order $10^{2}$, $10^{3}, 10^{4}$, and $10^{5}$ megohms. The lowest of these is first compared with a standard resistance of 10 megohms. This is then used as a standard to measure the $10^{3}$ megohms, the process being repeated for the higher resistance.

$E$ is usually a two-volt battery, and for accuracy the ratio of $R_{2}: R_{1}$ should not be much less than $10: 1$. The valve employed in these measurements is supplied by Philips Lamps, Ltd., and its chief characteristic, which makes it so suitable for such measurements, is that the grid current, when the grid bias is

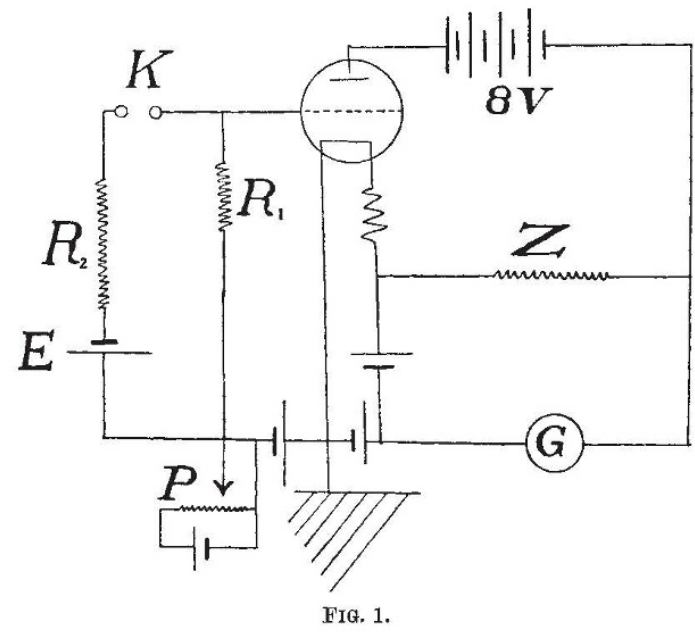

-2 volts, is less than $10^{-14}$ amp. The method cannot be employed for resistances above $10^{7}$ megohm, as resistances of a higher order are comparable with the grid filament resistance of the valve.

The potentiometer employed is by the Cambridge Instrument Co., Ltd., and a comparatively insensitive galvanometer ( 1 division per microamp.) is sufficient.

Further details of the method will be published later, in connexion with the work on ionisation measurements which are in progress.

University College,

J. A. C. Teegan.

NANCY HaYes.

Cork, Feb. 4.

\section{The Revival of Scholasticism}

I. IT is difficult to see just what is the meaning attached to "direct contact' in the statement that "we have no means of getting into direct contact with them [physical objects]" ("The Decline of Determinism", Nature, Feb. 13, p. 235). For, the fact that the sense-organs merely reflect objects is not a modern discovery: it was the basis of Francis Bacon's inductive philosophy. "Our method is continually to dwell among things soberly ; without abstracting or setting the understanding farther from them than makes their images meet." "For however men may amuse themselves, and admire or almost adore the mind; it is certain that, like an irregular glass, it alters the rays of things. . . ." "The capital precept for the whole conduct is this, that the eye of the mind be never taken off from things themselves; but receive their images truly as they are." "The mind is like a glass, capable of the image of the universe ... as the eye to receive the light." (Preliminaries, "De Augmentis Scientiarum ".)

In the "Anugitā Upanishad", one of the earliest known philosophical writings, it is repeatedly stated that the senses are conscious only of the qualities of 'objects', which are themselves merely appearances$M \bar{a} y \tilde{a}$; in effect, merely condensations or accumula- 